\title{
Contaminated Effect of Geomagnetic Storms on Pre-Seismic Atmospheric and Ionospheric Anomalies during Imphal Earthquake
}

\author{
Sagardweep Biswas ${ }^{1 *}$, Subrata Kundu1, Soujan Ghosh ${ }^{1}$, Swati Chowdhury1, Shih-Sian Yang2, \\ Masashi Hayakawa ${ }^{3}$, Suman Chakraborty ${ }^{4}$, Sandip K. Chakrabarti' ${ }^{1}$, Sudipta Sasmal ${ }^{1}$ \\ ${ }^{1}$ Indian Centre for Space Physics, Kolkata, India \\ ${ }^{2}$ Institute of Space Science, National Central University, Chinese Taipei \\ ${ }^{3}$ Hayakawa Institute of Seismo Electromagnetics Co. Ltd., UEC Alliance Center, Chofu, Tokyo, Japan \\ ${ }^{4}$ Physical Research Laboratory, Navrangpura, Ahmedabad, India \\ Email: ^sagar94m@gmail.com, mcqmld@gmail.com, soujanghosh89@gmail.com, chowdhuryswati3@gmail.com, \\ hayakawa@hi-seismo-em.jp, suman.chakrabarty37@gmail.com, sandipchakrabarti9@gmail.com, meet2ss25@gmail.com
}

How to cite this paper: Biswas, S., Kundu, S., Ghosh, S., Chowdhury, S., Yang, S.-S., Hayakawa, M., Chakraborty, S., Chakrabarti, S.K. and Sasmal, S. (2020) Contaminated Effect of Geomagnetic Storms on Pre-Seismic Atmospheric and Ionospheric Anomalies during Imphal Earthquake. Open Journal of Earthquake Research, 9, 383-402.

https://doi.org/10.4236/ojer.2020.95022

Received: May 27, 2020

Accepted: November 9, 2020

Published: November 12, 2020

Copyright $\odot 2020$ by author(s) and Scientific Research Publishing Inc. This work is licensed under the Creative Commons Attribution International License (CC BY-NC 4.0).

http://creativecommons.org/licenses/by-nc/4.0/ (c) (i) Open Access

\begin{abstract}
Study of seismo-ionospheric coupling mechanism demands the quiet geomagnetic condition to eliminate any kind of contamination in the lower atmospheric and ionospheric parameters. In this manuscript, we present the effect of back to back two geomagnetic storms before a strong earthquake happened in Imphal, India on January 4, $2016(\mathrm{M}=6.7)$. We studied the lower ionospheric irregularities for the duration of 31 days by computing the nighttime fluctuations in Very Low Frequency (VLF) radio signal received transmitter JJI $(22.2 \mathrm{kHz})$ in Japan at Ionospheric and Earthquake Research Centre \& Optical Observatory (IERCOO), Sitapur, India. We also studied the presence of Atmospheric Gravity Wave (AGW) in nighttime VLF signal in lower ionospheric heights and the same computed that from SABER/TIMED satellite. Two geomagnetic storms occurred on December 21, and 31, 2015. By the conventional analysis, we found that there is a significant decrease in nighttime trend and an increase in nighttime fluctuations around 15 days before the earthquake and just on the first storm and thus the pre-seismic effects on VLF signal gets contaminated due to the presence of storms. The wave-like structure in VLF fluctuations shows significant increase in intensity by using Fourier and Wavelet analysis before the earthquake. By analysis of SABER data, we found significant enhancement in AGW around 10 days before the earthquake. As the wavelike structures are coming from neutral acoustics reasons from pressure or temperature variations, this paper exhibits a significant example of contamination in ionospheric parameters due to geomagnetic storm where the acoustics parameters remain un-contaminated.
\end{abstract}




\section{Keywords}

Very Low Frequency, Wave Propagation, Earthquake Precursory, Atmospheric Gravity Wave, Geomagnetic Strom, SABER/TIMED

\section{Introduction}

There are a few hypothetical models for the Lithospheric-Atmospheric-Ionospheric Coupling (LAIC) mechanism, which consists of three types of channels, i.e. thermal, acoustics and electromagnetic channel [1] [2]. In the electromagnetic channel, sub-ionospheric Very Low Frequency (VLF) signal has a significant influence to understand this mechanism. The general hypothesis of this channel is that the electromagnetic perturbation in ionospheric heights modulates the VLF amplitude and phase which can be utilized to identify the pre-seismic irregularities. Abnormality in VLF amplitude and phase has been observed and modeled by several scientists [3]-[20]. After the historical Kobe earthquake 1995, Hayakawa and his team began to examine the VLF anomaly and observed a significant shift in the sunrise and sunset terminator times towards the nighttime before the earthquake [21] [22]. Later [23] used a different approach of the "Nighttime fluctuation method" to analyze the anomalies in the night-time VLF signal during earthquakes. Later [18] found significant fluctuation in VLF signal fluctuation during Sumatra earthquake, 2004. Later, VLF nighttime fluctuations have been statistically studied by using three methods in [16]. Three parameters namely 1) "trend" (as the monthly average of nighttime amplitude), 2) "dispersion" (standard deviation of the signal amplitude from this average) and 3) nighttime fluctuation has been studied to examine the pre-seismic anomalies. Similar studies have been performed for multiple earthquakes by [24].

Indian Centre for Space Physics (ICSP) is monitoring Sub-ionospheric VLF propagation characteristics extensively for more than 1.5 decade. Extensive works have been performed on VLF anomaly and seismic hazards for multiple baselines both statistically and case-wise. The first report of such seismogenic VLF perturbation was published for the Sumatra earthquake, 2004 by following the terminator time methods [25]. Later the correlation between "VLF Day Length" and seismic activity was established by [26] by using the VTX-Kolkata propagation path. The anomalies in "D layer preparation time (DLPT)" and "D layer disappearance time (DLDT)” before 1 - 2 day prior to the earthquake were observed by [27] [28] [29] [30] who have presented a simultaneous and comparative study of seismogenic VLF perturbation for multiple paths and earthquakes and performed a numerical modeling. The nighttime signal fluctuations have been also investigated by [31] [32].

In the acoustic channel, the most influential parameter of seismogenic irregularities is the atmospheric gravity wave (AGW) which can appear due to the atmospheric oscillation near the epicentral zone of corresponding earthquakes. 
These oscillations further travel to the upward direction and perturb the lower ionosphere [33]. Also, in lower stratosphere, this gravity wave perturbs the stratospheric wind and temperature and gets excited by convection system and jet stream and its wave period having a range from Brunt-Vaisala period to the inertial period. [34] first observed that VLF signals before earthquake exhibit atmospheric gravity wave signature of periods of few minutes to hours. They used data from Chofu, Shimizu and Maizuru receiving stations in Japan and found significant enhancement in the period range of gravity wave on 10 days prior to the earthquake on March 4, 2000. The AGW excitation was strong for Chufu and Maizuru station where for Shimazu, it was not clearly understandable. They use data from multiple receiving stations in Japan. And they found significant enhancement in the period range of gravity wave during seismic activity by observing AGW excitation on 10 days prior to earthquake. [35] reported the generation of planetary waves with period of 2 - 30 days associated with earthquakes. [36] [37] [38] [39] [40] also reported the evidences of presence of wavelike structure before large earthquakes. The first direct evidence has been reported by [41] using the Atmosphere Explorer-E (AE-E) satellite. He established the link between troposphere and ionosphere and reveals that AGW activity also can use as precursor signal of earthquake. [42] have also reported the AGW activity before the 2015 Nepal earthquake by using sub-ionospheric VLF signal anomaly in nighttime data by computing the Fast Fourier Transform (FFT) and wavelet power spectrum (WPS) methods. Direct evidences are also found by using the temperature profile in middle atmosphere by [43] by using ERA5 temperature profile data. They observed significant excitation in AGW happened a week before the Kumamoto earthquake on April 15, 2016 near the epicentral region. [44] also examined the signal from both ERA5 and SABER (Sounding of the Atmosphere by using Broadband Emission Radiometry) instruments by using atmospheric temperature profile to compare the generation of AGW for a oceanic earthquake in Tohoku on 2011 the land earthquake in Kumamoto. They found significant excitation in AGW on 4 - 8 days before the earthquake.

Ionospheric characteristics can be significantly modified by the influenced by the high-speed stream of solar wind due to the high-speed incoming plasma from the sun due to coronal mass ejections or coronal holes which associated with shock waves [45] named as geomagnetic storms. The ionosphere, middle atmosphere and tropospheric region feel a strong disturbance due to this geomagnetic storm [46] [47]. The impact of the storm on the ionosphere is caused by the penetration of energetic particles precipitations which suffer collisions with ionospheric plasmas and neutral elements and produces X-ray bremsstrahlung radiation resulting loss of energy [46]. This impact enhances the electron density in the ionosphere [46] [48] [49], resulting to the change in electromagnetic signal propagation which influence the signal absorption mechanism. The weaker version of this effect shows in lower ionosphere later the storm event or can be justified as post-storm effect. Including enhancement in charge density, 
ionospheric conductivity gradient, electromagnetic field distributions, ionization rate and reference height of $\mathrm{D}$ and $\mathrm{E}$ layers are also modified. All of these in the Earth Ionosphere Wave Guide (EIWG) characteristics which farther influence the VLF signal propagation [50].

In this manuscript, we try to understand the impact of a geomagnetic storm on pre-seismic anomalies in electromagnetic and acoustics channel by analyzing VLF radio signal and AGW excitation. The major objective of this study is to figure out the contamination in the pre-seismic effects due to geomagnetic storm and a possible method to eliminate such contamination to extract the seismogenic anomalies. We use fluctuations in VLF signal amplitude and temperature profile as observed from SABER satellite to figure out such possibilities during a moderately strong earthquake in Imphal on January 4, 2016. Two moderate geomagnetic storms occurred on December 21 and 31, 2015 before the earthquake. We compare both the VLF and AGW fluctuations and try to examine the contamination in the pre-seismic anomaly. The plan of the paper is the following. In Section 2, we present the data and methodology, In Section 3, we present the results and in Section 4, we conclude our findings.

\section{Data and Methodologies}

The earthquake occurred on January 4, 2016 at 04:35 local time (January 3, 2016, 23:05 UTC) in the north-east of India (Manipur). The epicenter was located at Tamenglong district which is $30 \mathrm{~km}$ away from Imphal (Geographic coordinates: $24.834^{\circ} \mathrm{N}, 93.656^{\circ} \mathrm{E}$ ) with a depth of $55 \mathrm{~km}$. The Richter scale magnitude of the EQ magnitude was $M=6.7$. In this work, VLF signal are received at Indian station IERCOO (Ionospheric and Earthquake Research Centre \& Optical Observatory), Sitapur (Geographic coordinate: $22.5112^{\circ} \mathrm{N}, 87.7865^{\circ} \mathrm{E}$ ) transmitted from a fixed frequency transmitter JJI, $22.2 \mathrm{kHz}$ at Japan (Geographic coordinate: $32.05^{\circ} \mathrm{N}, 131.51^{\circ} \mathrm{E}$ ). We choose the JJI-IERCOO propagation path as it passes over the epicenter and the earthquake preparation zone of the earthquake. The propagation path length is $\sim 4418 \mathrm{~km}$. The location JJI and IERCOO, propagation path, earthquake epicenter and the earthquake preparation zone are shown in Figure 1.

Figure 2 represents the temporal variation of VLF signal amplitude profile as a function of time in hours for the JJI-IERCOO path. In the left panel, we present two consecutive days December 29 and 30, 2015 in the inset we present the nighttime fluctuation between these two days. In the entire computation of VLF fluctuations, we use the local Indian Standard Time (IST) defined as IST = UTC + 05:30:00. In our computations, we take the duration 8 hours data starting from 20:00:00 IST to next day 04:00:00 IST. The right panel of Figure 3 shows the nighttime signal amplitude for the duration of 31 days starting from December 15, 2015 to January 16, 2016. For better understanding, the data files are stacked with an amplitude shift of $20 \mathrm{~dB}$. The red curve is the nighttime of the earthquake day where the blue curves are the same for the storm days. 


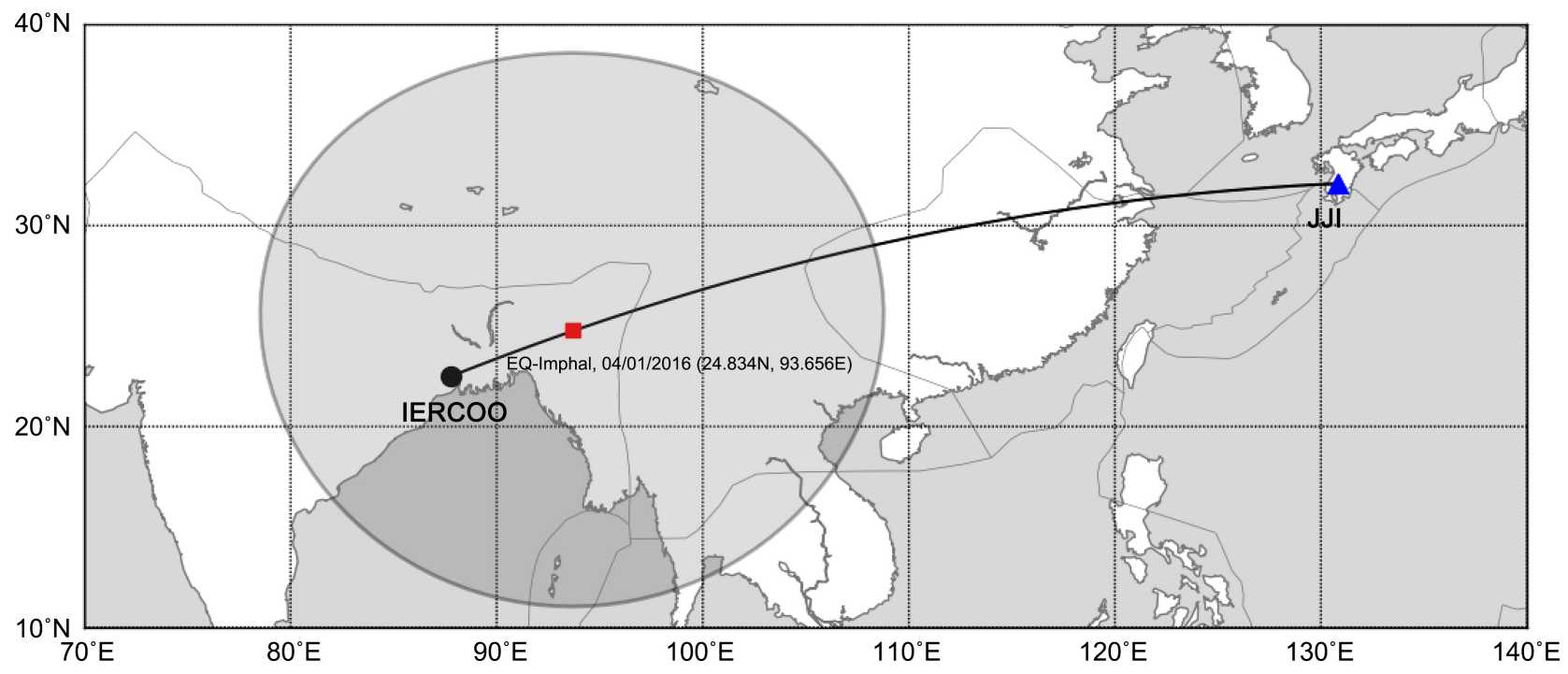

Figure 1. The location of transmitter JJI (blue triangle), receiving location IERCOO (black circle) and the wave-path between them. The location of earthquake epicenter and the earthquake preparation zone are marked with red cycle and the shaded circle respectively.
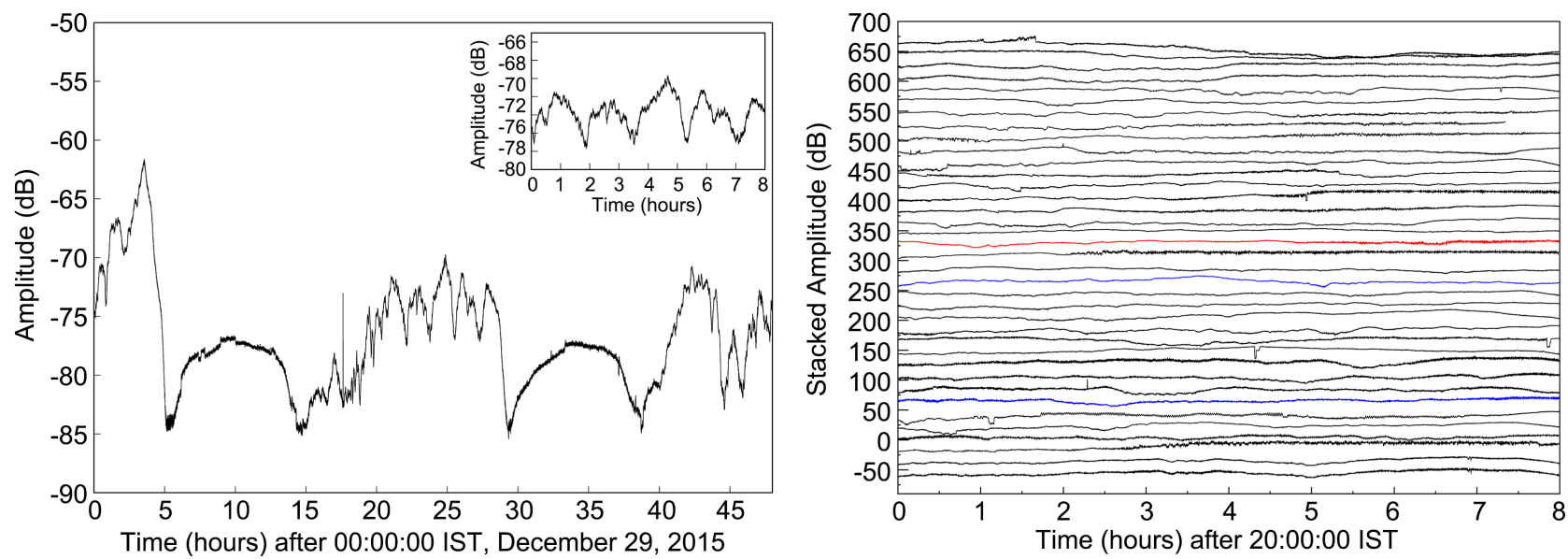

Figure 2. Temporal variation of VLF signal amplitude for JJI-IERCOO path. Left panel illustrates the diurnal variation of VLF amplitude as function of time for December 29-30, 2015. The data for the nighttime period (20:00:00 IST to 04:00:00 IST) between these two days are shown in the inset. The right panel shows the nighttime signal amplitude variation as a function of time in hours for 31 consecutive days. Data from December 15, 2015 to January 15, 2016 are plotted with a amplitude shift of $20 \mathrm{~dB}$ for better understanding. The red and blue lines represent the day of earthquake and geomagnetic storms.

It is found that the, the nighttime fluctuation analysis method for VLF signal is more effective for long propagation paths $(>1000 \mathrm{~km})$ in comparison to the daytime analysis techniques mainly Terminator Time (TT) method [51] [52]. This was verified by the results obtained by [3] and [53] where the VLF signal were used for longer path lengths from $\sim 5000$ to $\sim 9000 \mathrm{~km}$. For Imphal earthquake, as the path-length is around $\sim 4418 \mathrm{~km}$, we use the conventional nighttime fluctuation methods. As presented in Figure 2, we take the 8 hours of nighttime data for a period of 30 days. In the computation process, we take $A(t)$ as the VLF amplitude at time $t$ and $\langle A(t)\rangle$ is running average of amplitude at the same time $t$ taking over all 31 days. Now we compute the fluctuations 
as $d A(t)$ defined as $d A(t)=A(t)-\langle A(t)\rangle$. It is reported that for seismogenic effects, it is that is $d A(t)<0$ [23] [36] and so, we take the negative $d A(t)$ to compute the Nighttime Fluctuation (NF). Now Trend and Nighttime Fluctuation (NF) are defined by,

$$
\text { Trend }=\frac{\int_{N_{s}}^{N_{e}} \mathrm{~d} A(t) \mathrm{d} t}{N_{e}-N_{s}}
$$

and

$$
\mathrm{NF}=\int_{N_{s}}^{N_{e}}(\mathrm{~d} A(t))^{2} \mathrm{~d} t .
$$

Here $N_{e}$ and $N_{s}$ are Nighttime data ending and starting times. Normalization of these two parameters are done by $($ trend $-\langle$ trend $\rangle) / \sigma_{T}$ and $(\mathrm{NF}-\langle\mathrm{NF}\rangle) / \sigma_{\mathrm{NF}}$. Here $<>$ is defined as the average values of that parameter for 31 days and $\sigma^{\prime} s$ are the standard deviations of trend and NF for 31 days.

As the daytime ionosphere and the sub-ionospheric VLF signal is mainly controlled by the sun and solar flux, to examine the presence of wave like structure in VLF data, we choose the nighttime signal profile. We perform Fast Fourier Transform (FFT) and Wavelet analysis to investigate such phenomena. For FFT, we use a rectangular data window to observe the periodic structures and the wavelet analysis; we consider the Morlet mother wavelet function defined by,

$$
f(t)=\frac{1}{\sqrt[4]{\pi}} \exp \left(j \omega_{0} t\right) \exp \left(\frac{-t^{2}}{2}\right),
$$

In our analysis, we take the value of $\omega_{0}$ is 6 , the time sampling was 1 minutes and scale of 1 hour and $\omega_{0}$ is the non-dimensional frequency. The value is equal to 6 in this study to satisfy an admissibility condition. The admissibility conditions for the wavelet are that the function must have zero mean and be localized in both the time and frequency space [54]. For wavelet, we convert the input sample data from seconds to minutes and make to the total number of data sample in the power of 2 . We use the zero-padding method by adding zeros at the end of the true sample number until it reaches the power of 2 . We compute the Cone of Influence (COI) region inside the Wavelet Power Spectrum (WPS). The periodicity signatures outside of the COI region is due to the zero padding and are not genuine data and thus ignorable.

To compute the AGW excitation for direct observation, we use temperature profiles retrieved from observations of Sounding of the Atmosphere using Broadband Emission Radiometry (SABER) instrument on board the Thermosphere Ionosphere Mesosphere Energetics and Dynamics (TIMED) satellite around the earthquake region (Latitude range: $14^{\circ}$ to $35^{\circ} \mathrm{N}$ and Longitude range: $70^{\circ}$ to $110^{\circ} \mathrm{E}$ ) for the period December 15,2015 to January 15, 2016. SABER is a multi-channel radiometer designed to measure heat emitted by the atmosphere onboard of TIMED satellite. It is a geocentric satellite with a period of $96.8 \mathrm{mi}-$ nutes. The altitude resolution is $10 \mathrm{~km}$ to $180 \mathrm{~km}$ with an orbital altitude of 625 $\mathrm{km}$ circular $(+/-25 \mathrm{~km})$ and with orbital inclination of 74.1 degrees $(+/-0.1$ degree). The Limb Vertical Sampling Interval is $0.4 \mathrm{~km}$ for this instrument. 
SABER cover $50^{\circ} \mathrm{S}$ to $80^{\circ} \mathrm{N}$ while in Northward view and $50^{\circ} \mathrm{N}$ to $80^{\circ} \mathrm{S}$ in Southward view and on an average, it gathers data from $50^{\circ} \mathrm{N}$ to $50^{\circ} \mathrm{S}$ latitude range. In this study, we compute the potential energy $\left(E_{p}\right)$ associated with the gravity waves from the temperature profile. According to [55] [56] and [57] the satellite-based gravity wave analysis can be made by these methods. At first the background data is computed by fitting the individual temperature profile with least square fit (LSF). The estimation of LSF is made by taking the logarithm of the individual profile. Then a three-degree polynomial is fitted with logarithm profile and subtracted the fitted profile from the logarithm profile to obtain the residual. To remove the noise and other waves a $4 \mathrm{~km}$ box filter is applied to the residual and then the filtered residual is added back to the fitted profile. The antilog of the final fitted profile is called the LSF. The sum of the wave number 0 5 components is considered as the background temperature $\left(T_{0}\right)$. The perturbation temperature $(T)$ is obtained by subtracting the background temperature ( $\left.T_{0}\right)$ profile from the original profile. Now the gravity wave associated $E_{p}$ is obtained by the values by Equation (1).

$$
E_{p}=\frac{1}{2}\left(\frac{g}{N}\right)^{2},
$$

where $g$ is the acceleration due to gravity and $N$ is the Brunt Väisälä Frequency defined by,

$$
N^{2}=\frac{g}{T_{0}}\left(\frac{\partial T_{0}}{\partial z}+\frac{g}{c_{p}}\right),
$$

where $z$ is the altitude and $c_{p}$ is the specific heat at constant pressure.

To check the geomagnetic conditions, we use various geomagnetic indices data obtained from the NASA OMNIWEB archive. The geomagnetic indices $D_{\mathrm{st}}(\mathrm{nT}), K_{p}$ and $A_{p}$ during December 15, 2015 to January 15, 2016 are shown in Figure 3.
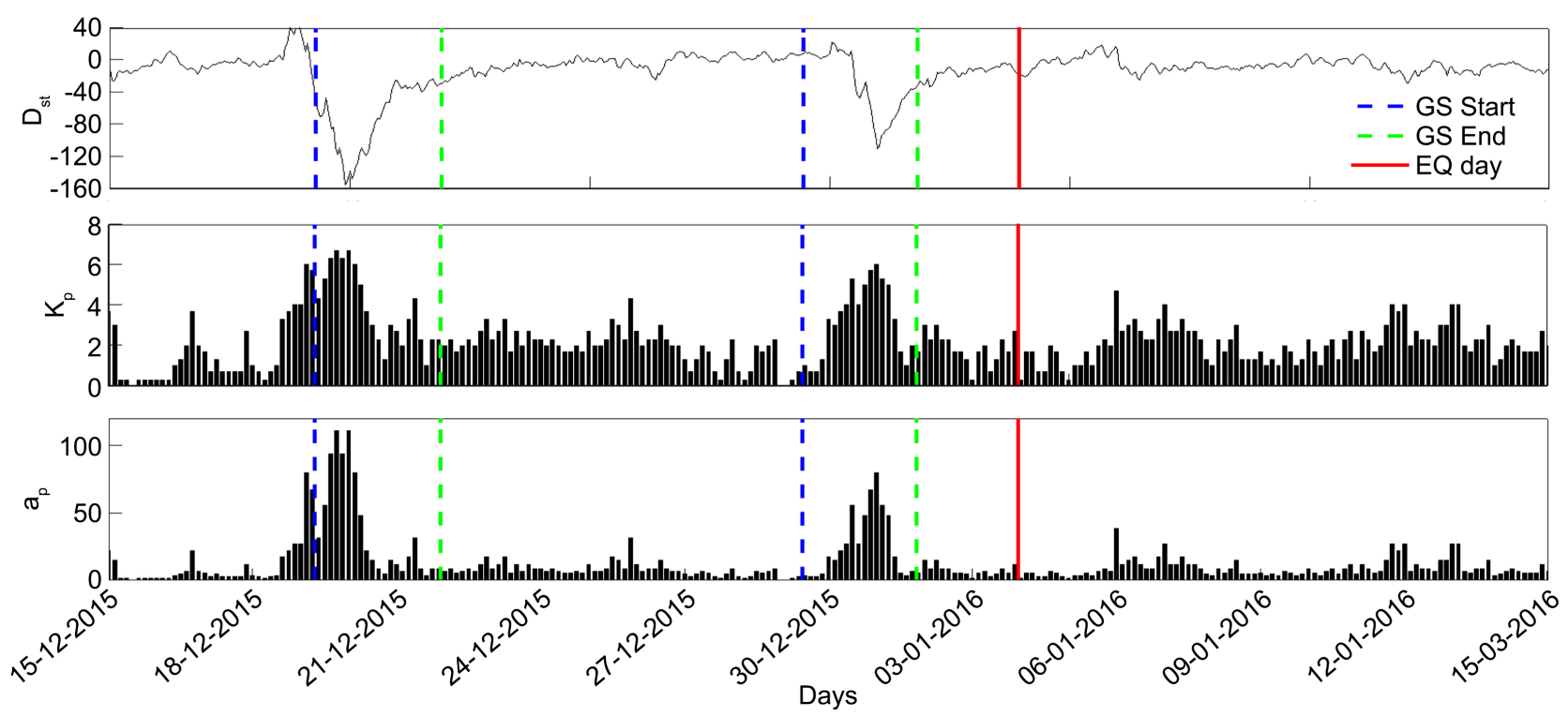

Figure 3. The variation of the geomagnetic indices from December 15, 2015 to January 15, 2016. 


\section{Result}

The normalized Trend (top) and NTF (bottom) as a function of day number are shown in Figure 4. Along X-axis, the "0" day number is treated as December 31, 2015 night to January 1, 2016 early morning. The days of the geomagnetic storms and earthquake are marked with "S" and "Eq" respectively. It is evident that there is a significant depletion in trend (below $2 \sigma$ level) and enhancement in NF (above $2.5 \sigma$ level) on the day of first storm (December 21, 2015). As it is on both pre-seismic and a geomagnetically active day, this abnormality cannot be correlated with individual event. The next enhancements occur on the day of the earthquake (January 3 night to January 4, morning) which is after three days of second geomagnetic storm (January 31,2015$)$ in both Trend $(2.5 \sigma)$ and NF $(3 \sigma)$. This second case shows comparatively better contaminating effect due to the presence of post-storm and pre-earthquake effects. Thus, VLF fluctuation seems highly contaminated and it is difficult to distinguish.

It is evident from Figure 3 that the recovery time of $D_{\mathrm{st}}$ index indicates for both the storms are almost 2 days after the main phase. As the first storm is rather stronger (maximum $\left.D_{\mathrm{st}} \sim 160 \mathrm{nT}\right)$ in comparison to the second one $\left(D_{\mathrm{st}} \sim\right.$ $100 \mathrm{nT}$ ), the immediate impact on lower ionosphere and thus in VLF signal with high Trend and NTF on December 21, 2015 is justifiable with the storm intensification. As the second storm is moderate and also close to the pre-seismic proximity situation, the effect during second storm is a mixed outcome. Also, the fluctuation in the VLF during the second storm is during the recovery phase. The enhancement of NF is also larger for second case. As reported previously that geomagnetic storm shows negative fluctuations in trends [50] but in this case we observe positive enhancement for the second storm. We can anticipate that the pre-seismic and moderate storm effect together create so much complexity in the ionosphere which generates some different results from the result for the independent storm and independent seismic events.

To examine the evidences of wavelike structures (AGW) in the VLF signal during nighttime we performed the FFT and Wavelet analysis by VLF nighttime signal during this period. We measured the wave like periodicity structure present in signal by both FFT and WPS up to earthquake date. We do not present the post-earthquake story as we are mainly interested the contamination in the precursors only. The resultant FFT spectrum is shown in Figure 5. Periodicity of 60 minutes is observed on 27 December 2015 night which is the signature of AGW.

The Wavelet power density spectrum is shown in Figure 6. It is evident that the most prominent wavelike structure with the similar periodicity that of FFT is found on December 27-28, 2015. A comparatively lower intensification also presents during December 22-23 and 24-25, 2015 with similar periodicity of $\sim 60$ minutes which indicates the presence of AGW in VLF signal. So the major excitation in AGW is after the first geomagnetic storm on December 21, 2015 and before the second storm on December 31, 2015 and the earthquake on January 5, 
2016. As the fluctuations are coming from ionospheric origin and that can be contaminated by geomagnetic storm, to validates this wave like structures in FFT and WPS, we use a direct observation of AGW generates from the acoustics origin by changing the pressure and temperature profile of atmosphere.
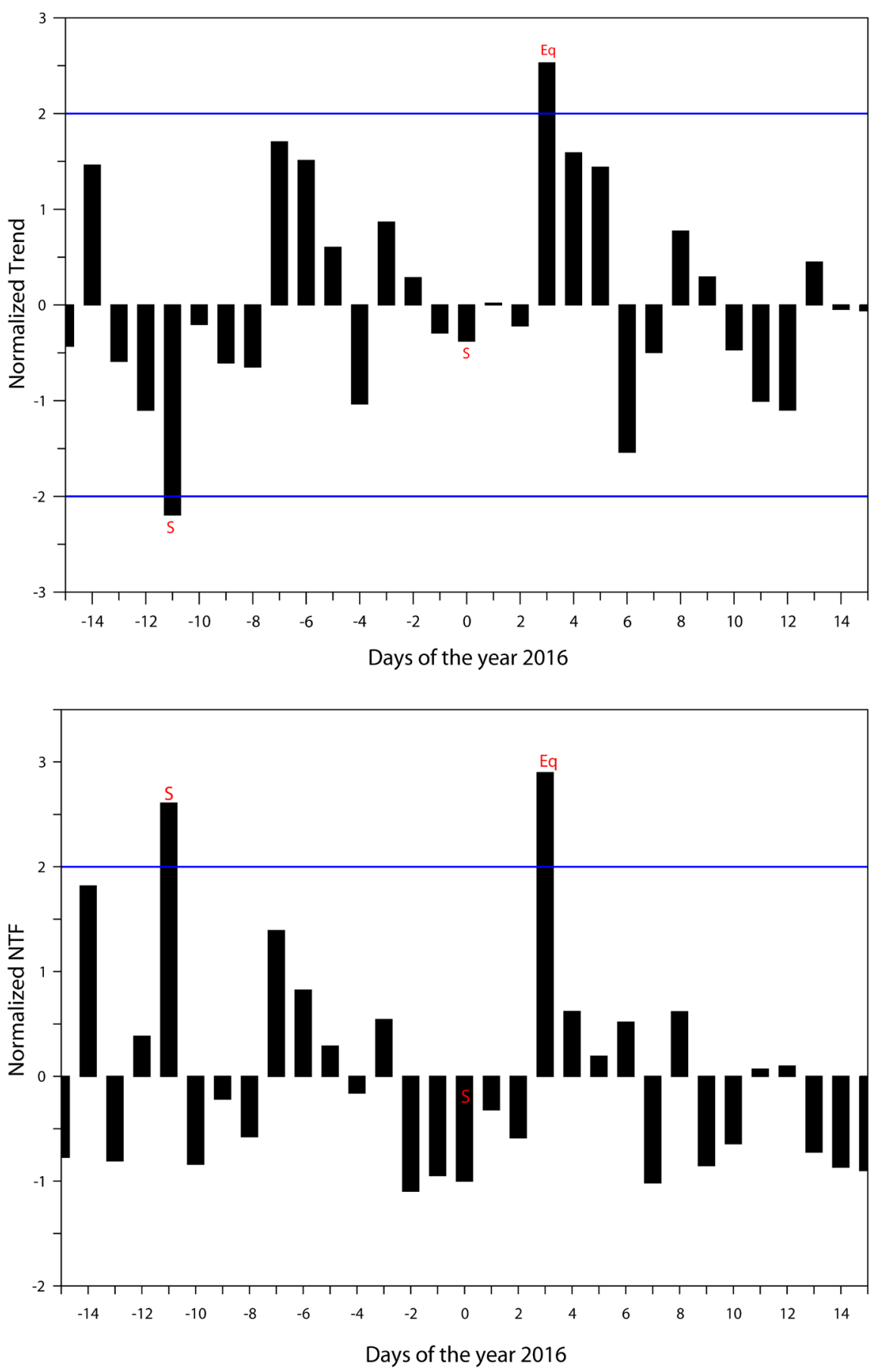

Figure 4. Normalized Trend (top) and NTF (bottom) as a function of day number during December 15, 2015 to January 15, 2016. The "0" denotes the December 31, 2015 night to 1 January, 2016 early morning. "S" and "Eq" denote the nighttime of storm and earthquake day. The horizontal blue lines represent the $\pm 2 \sigma$ where $\sigma$ is the standard deviation. 


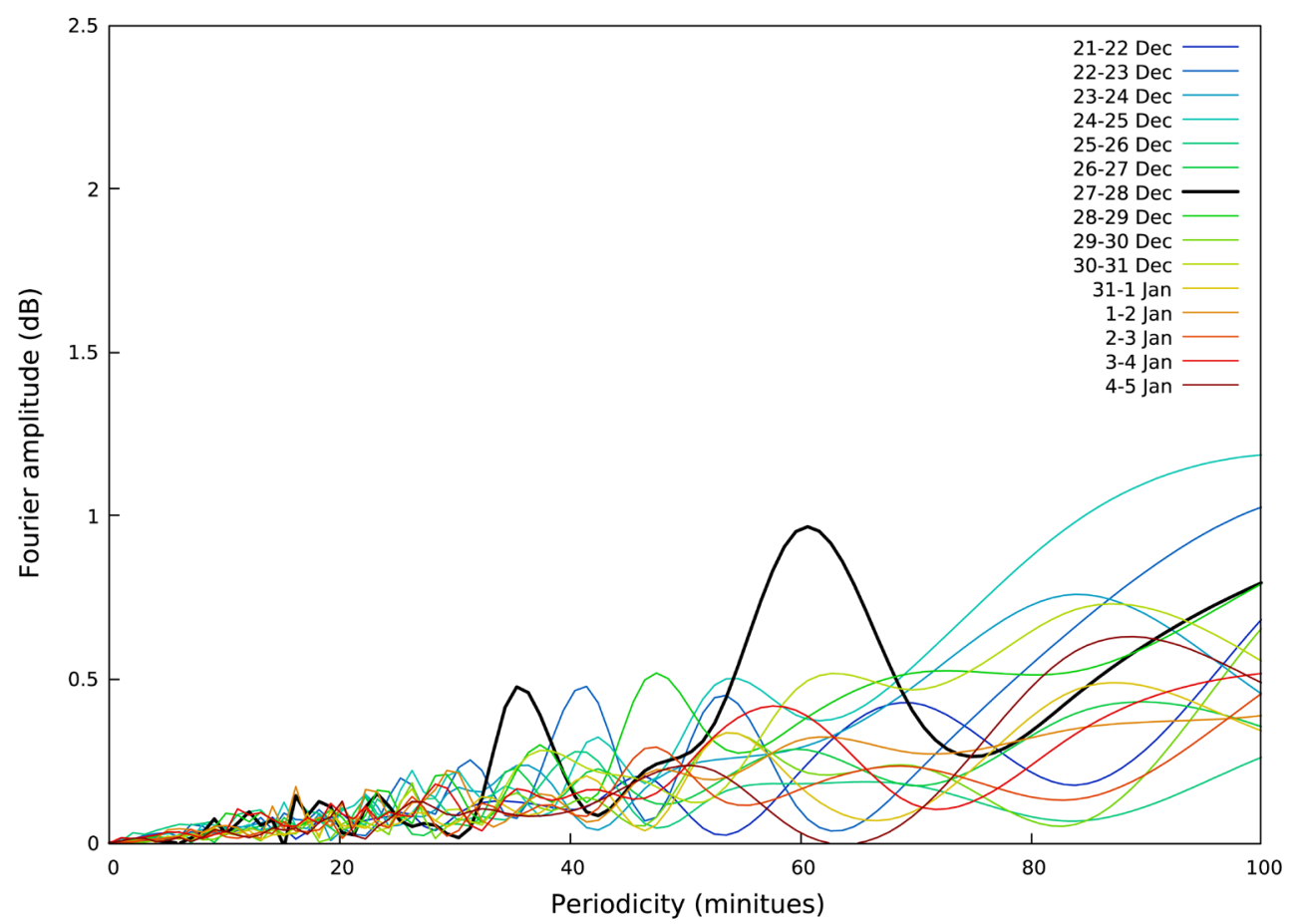

Figure 5. Normalized Fast Fourier Transform (FFT) spectrum of VLF signal from December 21, 2015 to January 5, 2016. The X axis indicates the periods in minutes and $\mathrm{Y}$-axis indicates the Fourier amplitude in $\mathrm{dB}$. Strong amplitude around 60 minutes of periodicity (AGW) is observed found in the nighttime on 27-28 December, 2015.
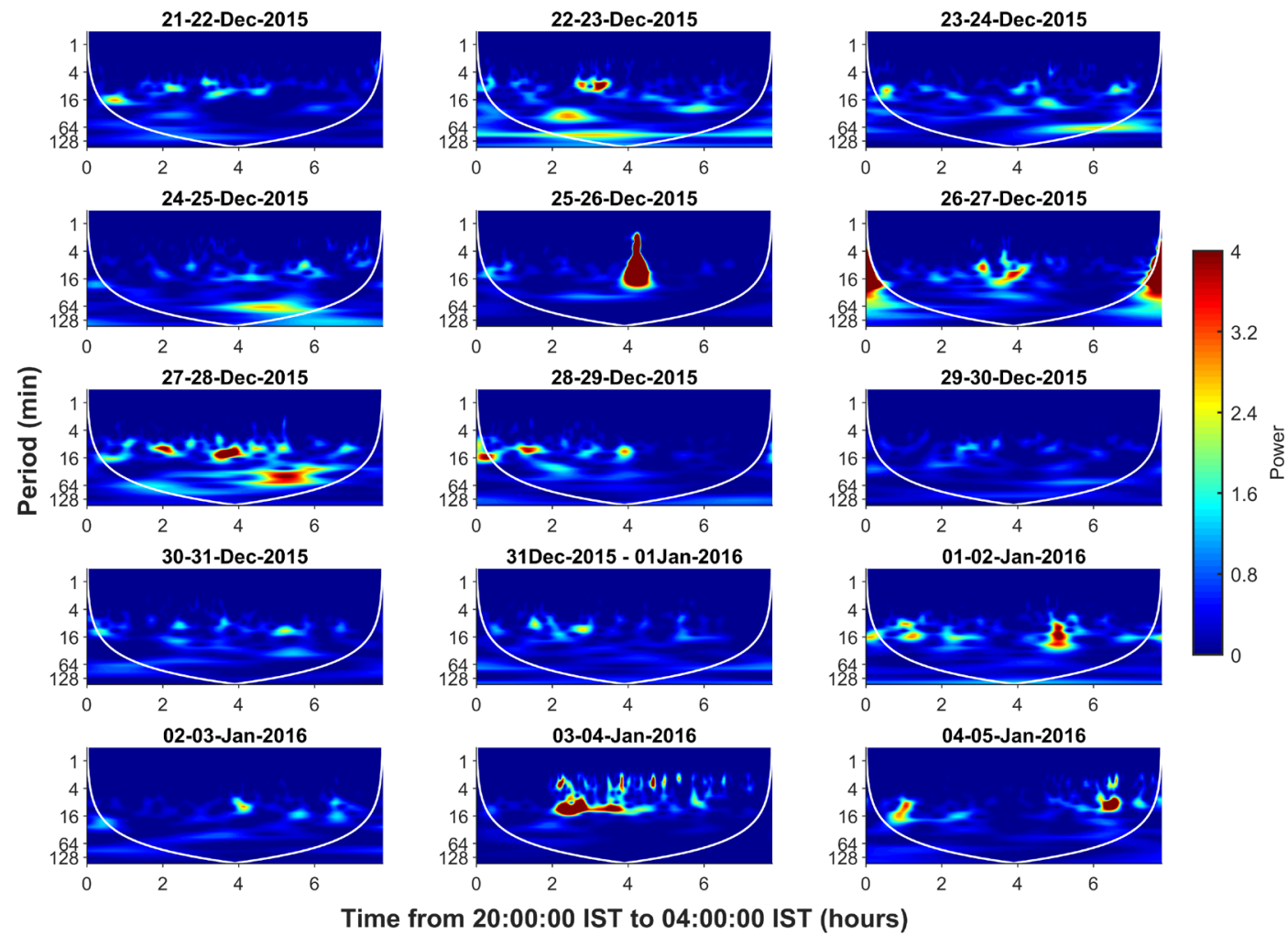

Figure 6. Wavelet power density spectrum of nighttime VLF data from December 21, 2015 night to January 5, 2016. The X-axis denotes the time in hours, $\mathrm{Y}$-axis indicates periodicity of wave structure in minutes and the color-bar represents the power. The WPS shows maximum intensification in AGW of periodicity $\sim 60$ minutes on December 27-28, 2015. 
To examine the direct evidences of AGW, we compute the four dimensional $E_{p}$ values, i.e., over space (three dimension) and time, from the SABER temperature profile for the stratospheric altitude of 30 - $50 \mathrm{~km}$ December 15, 2015 to January 15, 2016. Firstly, the time altitude profile is shown in Figure 7(a), Figure 7 (b). As the satellites data are procured in the universal time format. It is clearly evident that $E_{p}$ is significantly increased at an altitude of 44 to $46 \mathrm{~km}$ around December 24-27, 2015 (UTC). For better understanding, we also zoom the region "A" portion, which is shown in Figure 7(b) (bottom). The date of the earthquake is marked with magenta dashed vertical line (January 3, 2016, UTC).

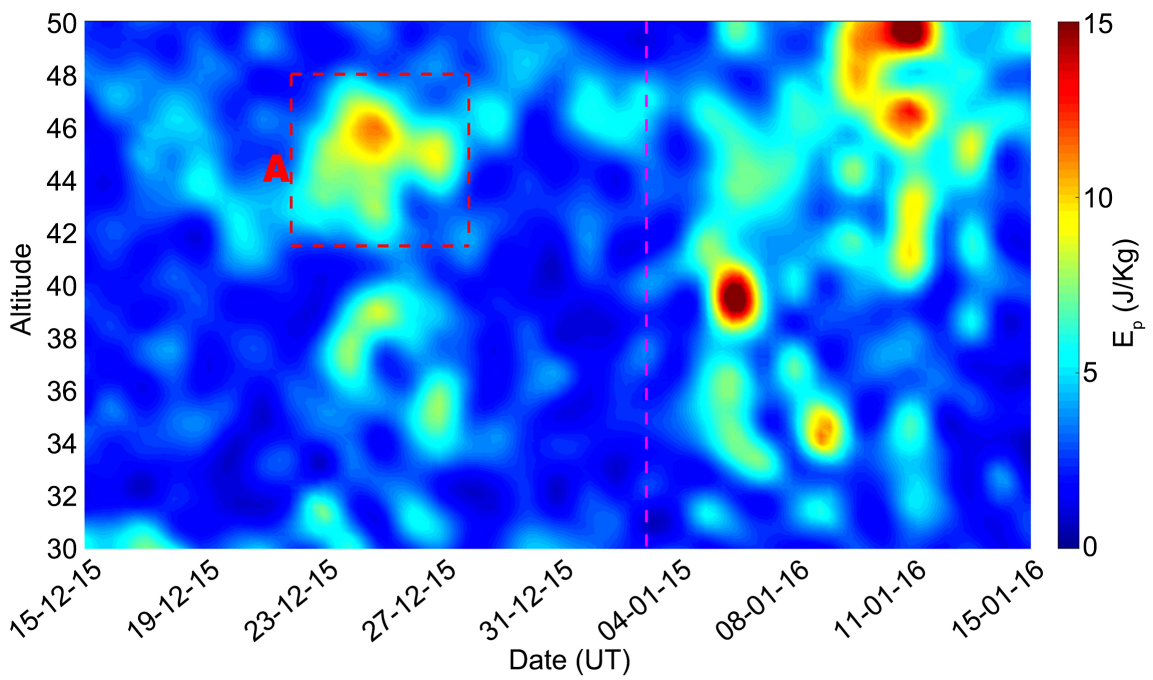

(a)

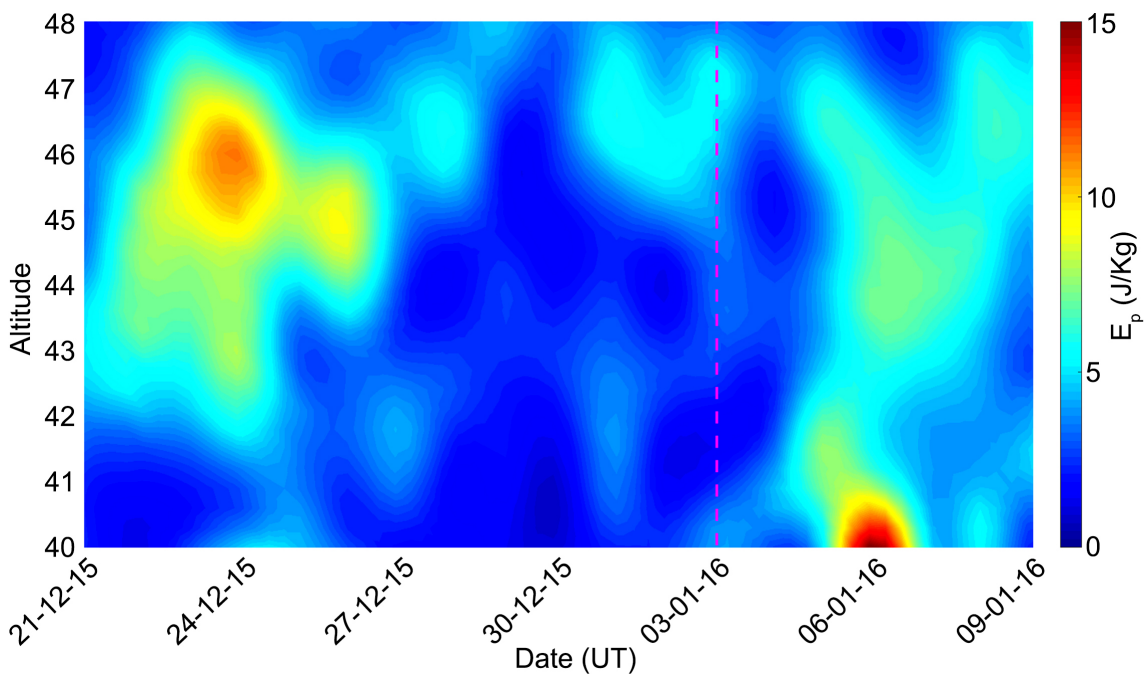

(b)

Figure 7. (Top: a) Altitude profile of Potential Energy $E_{p}$ derived from the SABER temperature profile during the period December 15, 2015 to January 15, 2016 as presented in Universal time. The red box represents the region " $A$ " which shows significant increase in EP. The magenta dashed line represents the EQ day in Universal date time format (January 3, 2016). (Bottom: b) Prominent AGW activity period during December 24-27, 2015 in Universal date time format (Zoom in on region " $A$ "). 
The initial outcomes from temperature profiles are shown in Figure 8. Figure 8(a) shows the temperature profile with fitted profile, Figure 8(b) $T$, Figure 8(c) $N^{2}$ and Figure 8(d) $E_{p}$ for December 24-27, 2015 in the Universal Date Time format.

The maximum value of $E_{p}$ enhancement is near about $12 \mathrm{~J} / \mathrm{kg}$. To examine the locational dependency of the AGW, the latitudinal and longitudinal variation $E_{p}$ at an altitude of $45 \mathrm{~km}$ during December 21, 2015 to January, 92016 are presented in Figure 9(a), Figure 9(b). The horizontal magenta lines represent the latitude and longitude of the epicenter of earthquake.

It is evident from Figure 9(a), Figure 9(b) that the enhancement in $E_{p}$ is maximum around the epicenter before the earthquake. The $E_{p}$ enhancement is not fixed but getting transferred. The enhancement starts at lower altitude of $\sim 20^{\circ} \mathrm{N}$ (Top panel of Figure 9) and then it starts to transfer to the higher altitude. The $E_{p}$ reaches its maximum at $23^{\circ} \mathrm{N}$ latitude on December 24, 2015 and is spread over up to $26^{\circ} \mathrm{N}$ around the epicenter. After December 24, it starts to decrease and again gets increased around December 27 in a lower latitude region.

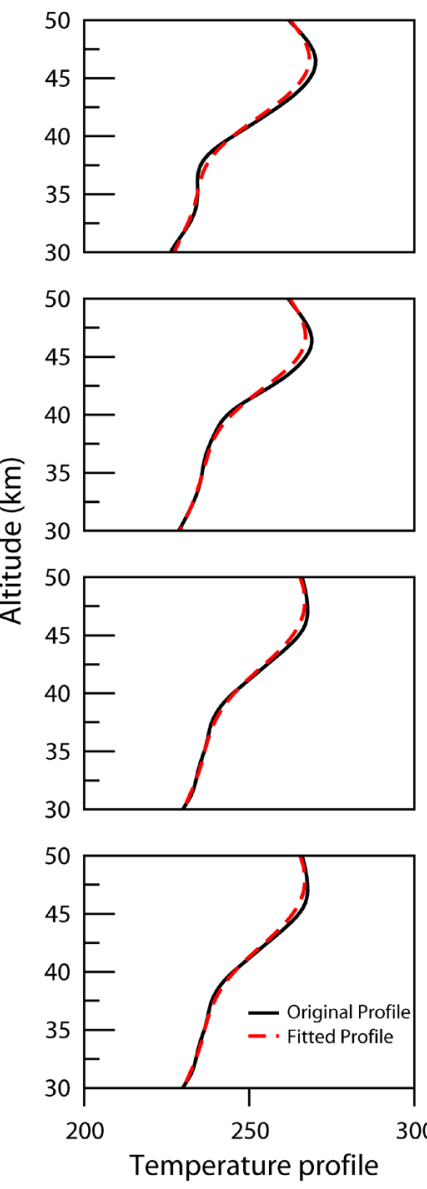

(a)
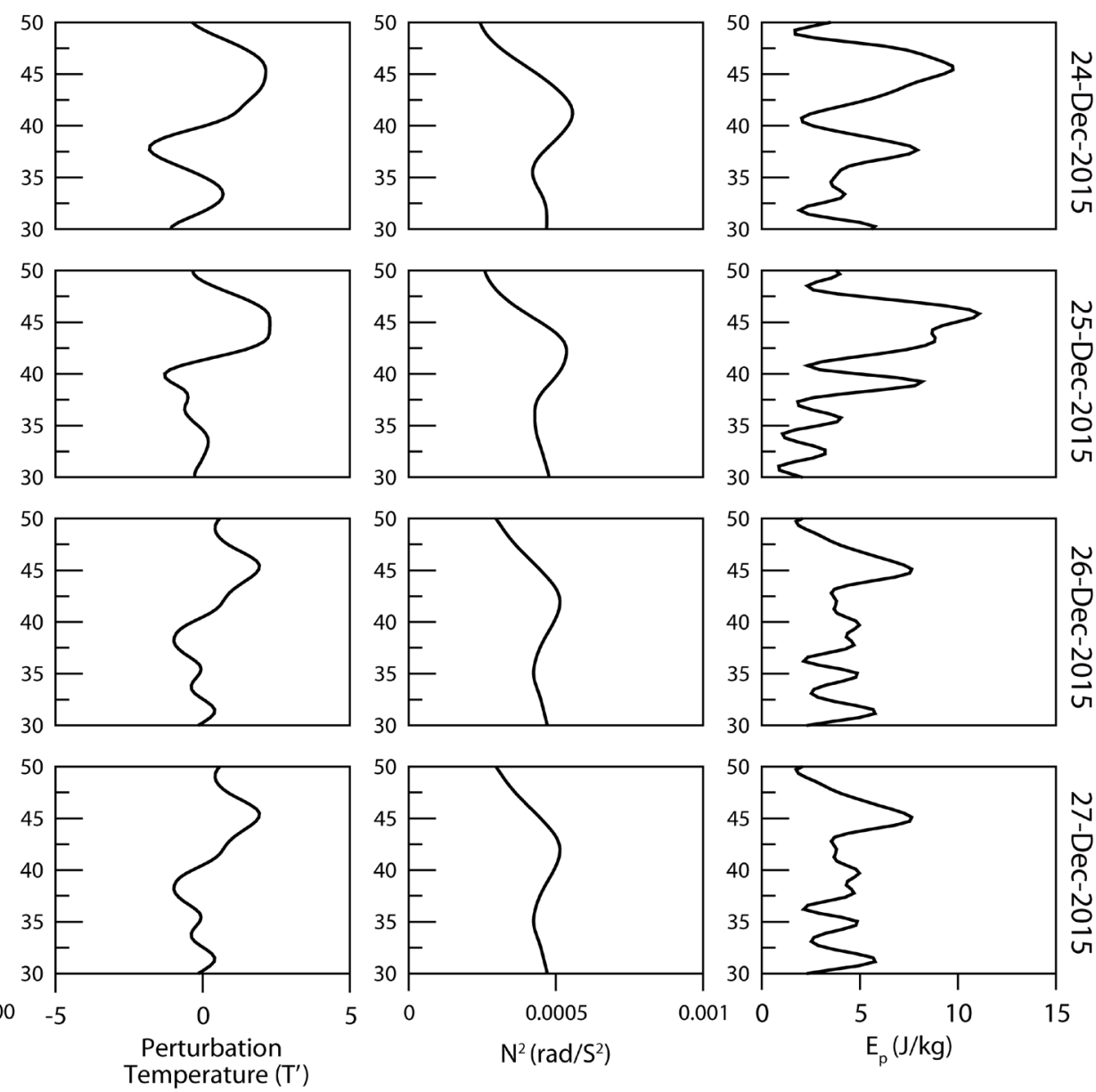

(b)

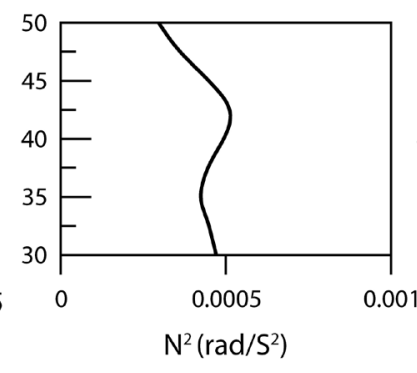

(c)

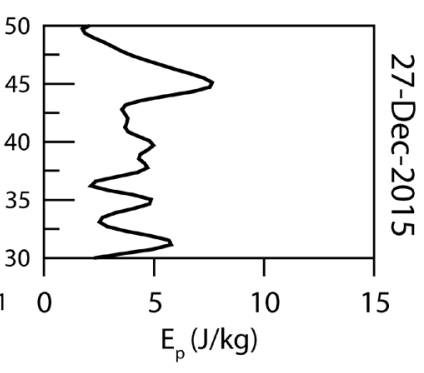

(d)

Figure 8. Vertical profile of (a) temperature profile with fitted profile, (b) $T^{\prime}$, (c) $N^{2}$ and (d) $E_{p}$ for (1) December 24, 2015, (2) December 25, 2015 (3) December 26, 2015 and (4) December 27, 2015. 


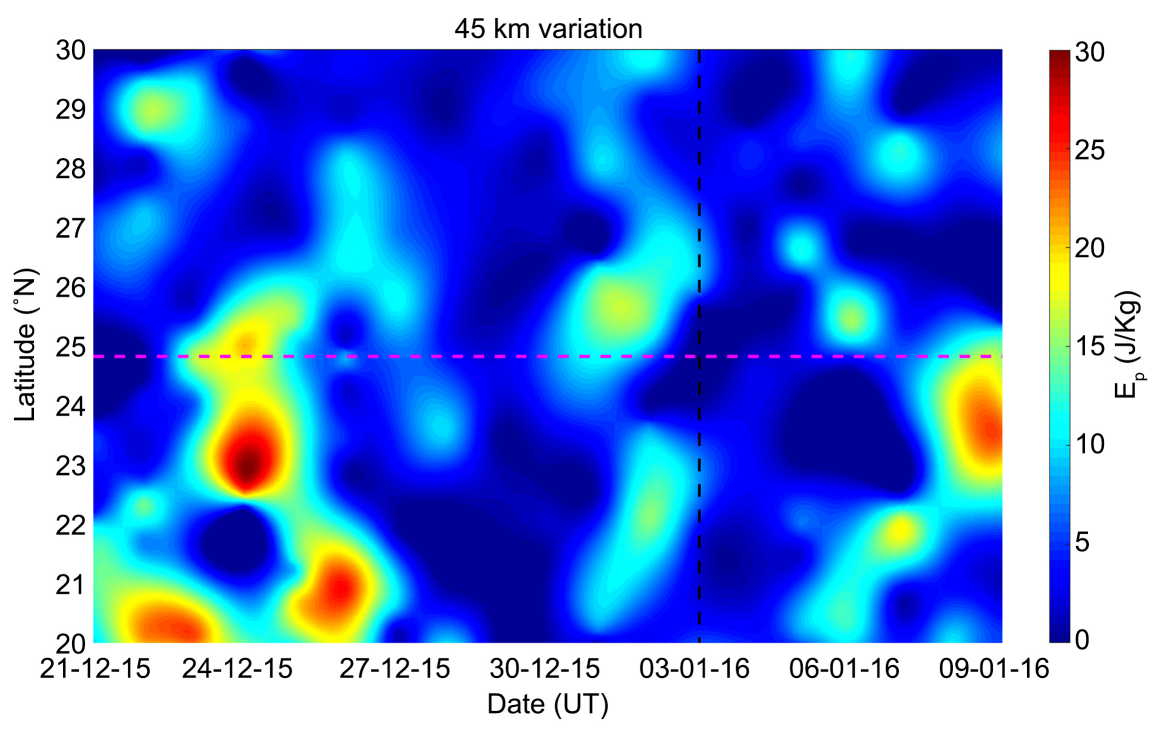

(a)

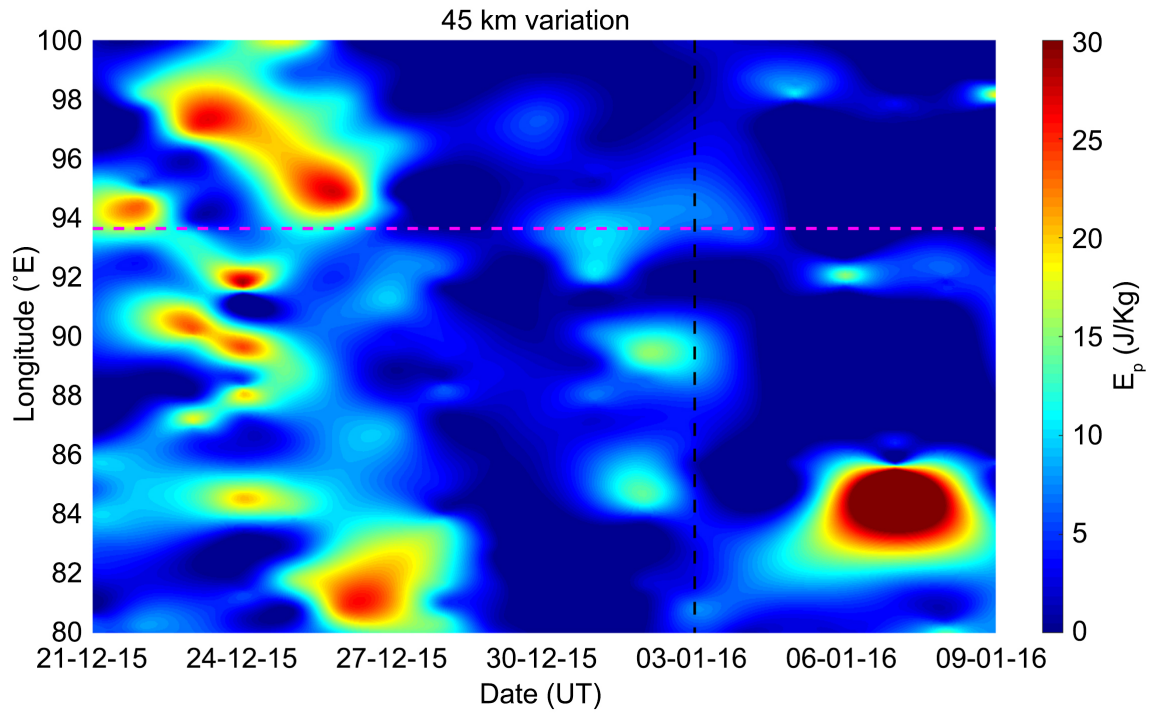

(b)

Figure 9. (Top: a) Latitudinal ad (Bottom: b) longitude variation of the potential energy $E_{p}$ at an altitude $45 \mathrm{~km}$. The magenta horizontal lines represent the latitude and longitude of the epicenter and the vertical dashed line denote the day of the earthquake (UTC).

In and around the epicenter, the transfer is not symmetric in nature. The longitudinal variation is rather different from the latitudinal variation. Around the epicenter, the $E_{p}$ becomes maximum on December 27, 2015 at $\sim 94^{\circ} \mathrm{E}$. However instead of continuous transformation, the $E_{p}$ around epicenter is rather discrete and forms clusters around the epicenter from $88^{\circ} \mathrm{E}$ to $98^{\circ} \mathrm{E}$. It is evident that during the December 24-27, 2015, the $E_{p}$ gets transferred from the higher altitude to the lower which is different than from the latitudinal variation.

To examine the distribution of $E_{p}$ more precisely, we draw the spatial variation of $E_{p}$ over a map. Figure 10 shows the variation of $E_{p}$ values from December 17, 2015 to January 15, 2016 over a map of India and its territory. It is clearly 
visible from Figure 10 that the enhancement of $E_{p}$ is maximum during December 24-27, 2015 over the epicenter. It is also evident that the generated wave are coming from the North-East (December 23, 2015), cover widely over the epicenter (December 25, 2015) and faded away in the direction of South-East of Indian landmass. This is consistent with the overall AGW variation as shown in Figure 7(a), Figure 7(b) and Figure 9(a), Figure 9(b).

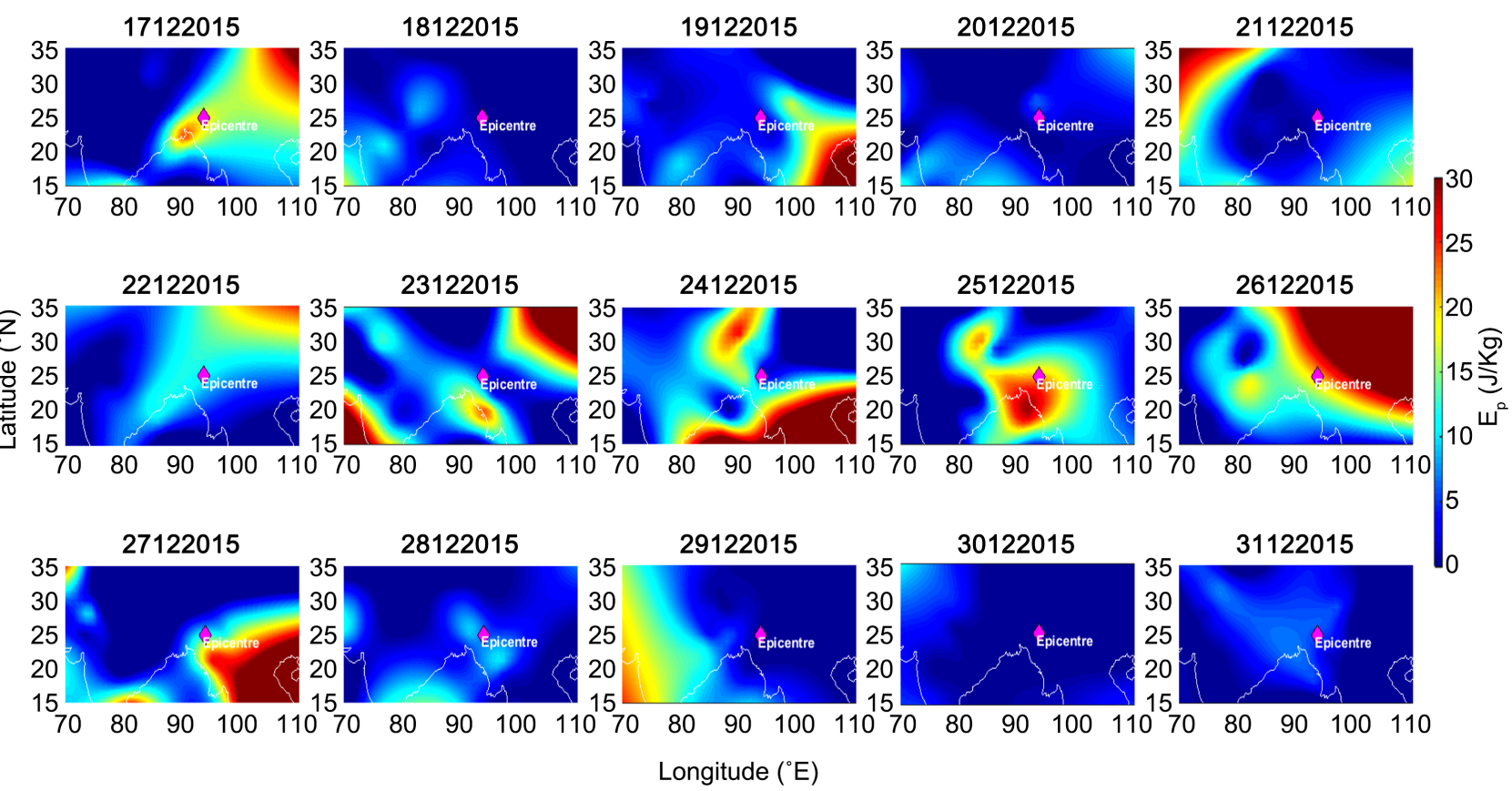

(a)
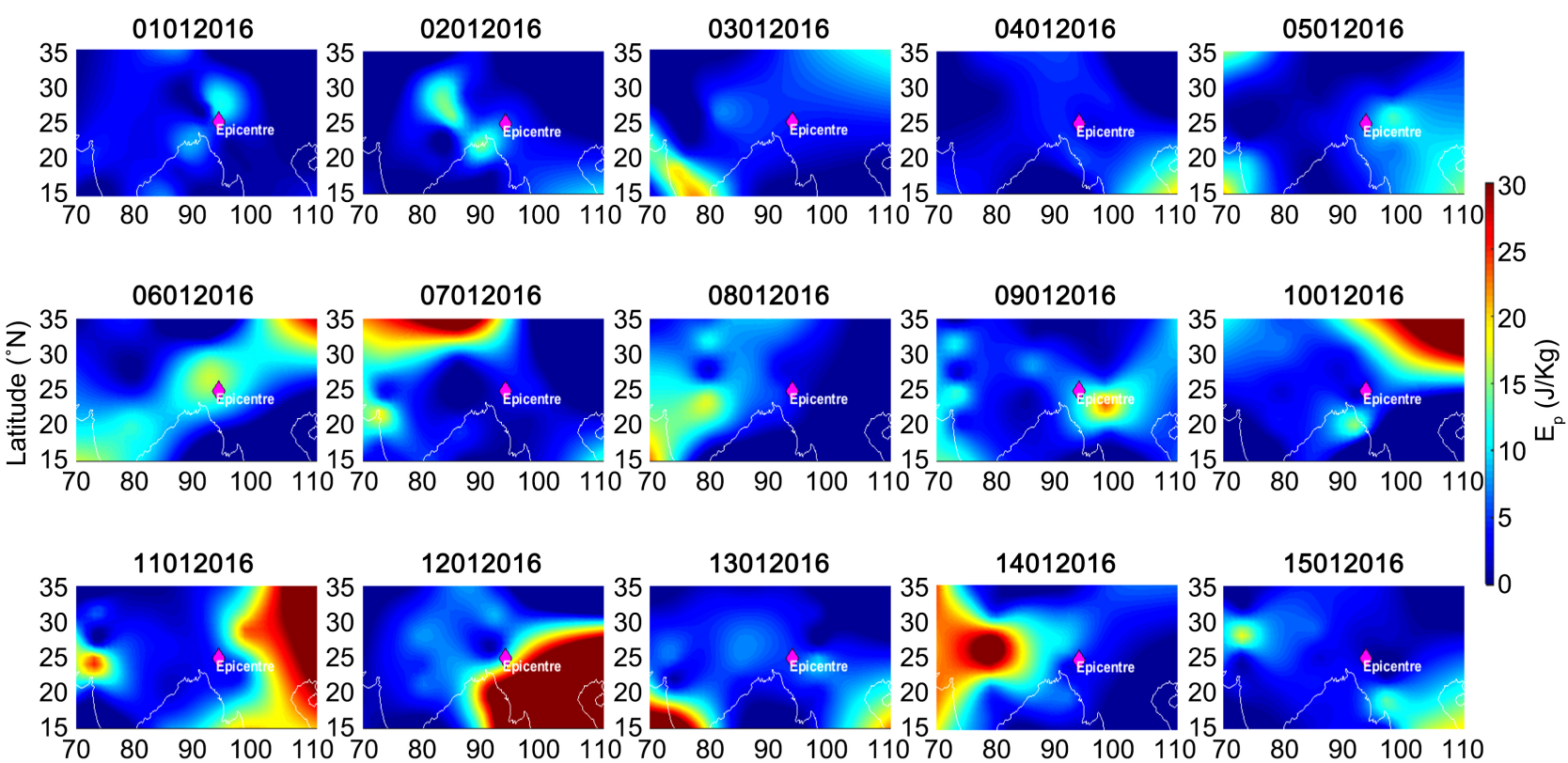

Longitude $\left({ }^{\circ} \mathrm{E}\right)$

(b)

Figure 10. Variation of Potential energy over Indian landmass during December 17, 2015 to January 15, 2016. 


\section{Conclusions}

In this manuscript, we try to figure out the possible pre-seismic phenomena during a strong earthquake in Manipur, India on December 4, 2015 (IST). Prior to the earthquake, moderate to strong geomagnetic storms happened on December 21 and December 31, 2016 for which the seismogenic signal got contaminated. We proceed in a different approach where we examine the most useful parameter in LAIC mechanism which can be used to identify the contaminated seismogenic signals. Also, we try to eliminate the storm induced phenomena in our results. We mainly use two channels in LAIC mechanism viz. 1) electromagnetic channel and 2) acoustics channel. For electromagnetic channel, we use sub-ionospheric VLF propagation technique for JJI-IERCOO baseline and compute the nighttime Trend and NTF from the conventional methods for a period of December 31, 2015 to January 15, 2016. It is found that the Trend and NTF gets anomalous on the first storm on December 20-21 night and on the day of the earthquake i.e. January 3-4. Also, the Trend in positive during the second storm implies that apart from the storm, and the seismogenic wave also has an impact on the nighttime signal amplitude. It is difficult to anticipate the effects whether seismogenic or due storm induced plasma variation as the effects in lower ionosphere can be a combined effect of both the earthquake and storm. We notice that the effect of the first storm which is stronger, the impact on VLF signal is immediate in comparison to the second storm which is weaker. To verify this effect, we use the acoustics channel and compute the AGW fluctuations from VLF signals using FFT and Wavelet analysis. From both eh FFT and Wavelet analysis, we observe that there is strong signature of AGW with periodicity of $\sim 60$ minutes. It is mostly acceptable that the generation mechanism of AGW is majorly from the acoustics origin where the temperature and pressure gradient waves move to the higher attitude. To justify the above statement, we compute the potential energy $\left(E_{p}\right)$ of AGW as compute from the atmospheric temperature profile as observed by SABER/TIMED instruments. We observed that the $E_{p}$ gets enhanced during December 24 to 27, 2015 which is ahead of earthquake. To justify these results, spatio-temporal profile of $E_{p}$ is computed (Figures 7-10) where it is observed that the increase in the potential energy is over the earthquake epicenter with a transport mechanism around the same.

We anticipate that the ionospheric effects are of course getting contaminated due to the geomagnetic storm where the ionospheric charge particles and plasma gets perturbed significantly. So, in this case, the VLF fluctuation is rather contaminated in nature and it is difficult to assign this effect in Trend/NTF as pre-seismic. However, as the effects of acoustics channel (AGW hypothesis) are consistent in both FFT/WPS and SABER/TIMED, we can say that, AGW hypothesis are rather non-contaminated in this case. As the sources of stratospheric AGW are the neutral winds, it is most likely to remain unperturbed during the storm. Though there is an example from [58] where evidences of AGW have been found after 1 - 15 days of storm as observed from wind speed, atmospheric 
density and pressure. It is also evident from Figures 7-10 that there is also example of post seismic AGW excitation. This could have several reasons starting from several aftershocks and many other meteorological phenomena [43] [59]. As, in this manuscript, we concentrate mainly the contamination in pre-seismic effects, we are excluding this part from our discussion. We will do it in future. Also, in future we will choose more earthquakes which have perturbations due to geomagnetic storms where we can apply more parameters in thermal, acoustics and electromagnetic channels of LAIC to figure out this seismogenic contamination.

\section{Acknowledgements}

The authors acknowledge DST-INSPIRE fellowship, DST-SERB fellowship and Govt. of West Bengal for financial supports, SABER and their scientific team and NASA OMNIWEB for providing scientific data. We thank to Japan trust and National Institute of Information and Communication Technology (NICT), Japan and Hayakawa Institute of Seismo-Electromagnetis Co. Ltd (Hi-SEM) for scientific supports.

\section{Conflicts of Interest}

The authors declare no conflicts of interest regarding the publication of this paper.

\section{References}

[1] Pulinets, S.A. and Boyarchuk, K. (2004) Ionospheric Precursors of Earthquakes. Springer, Berlin, 215.

[2] Pulinets, S. and Ouzounov, D. (2011) Lithosphere-Atmosphere-Ionosphere Coupling (LAIC) Model-A Unified Concept for Earthquake Precursors Validation. Journal of Asian Earth Sciences, 41, 371-382. https://doi.org/10.1016/j.jseaes.2010.03.005

[3] Gokhberg, M.B., Gufeld, I.L., Rozhnoi, A.A., Marenko, V.F., Yampolsky, V.S. and Ponomarev, E.A. (1989) Study of Seismic Influence on the Ionosphere by Super Long-Wave Probing of the Earth Ionosphere Waveguide. Physics of the Earth and Planetary Interiors, 57, 64-67. https://doi.org/10.1016/0031-9201(89)90214-8

[4] Hayakawa, M. and Fujinawa, Y. (1994) Electromagnetic Phenomena Related to Earthquake Prediction. Terra Sci. Pub. Co., Tokyo, 67-71.

[5] Hayakawa, M. and Sato, H. (1994) Ionospheric Perturbations Associated with Earthquakes as Detected by Subionospheric VLF Propagation. In: Hayakawa, M. and Fujinawa, Y., Eds., Electromagnetic Phenomena Related to Earthquake Prediction, Terra Sci., Tokyo, 391-397.

[6] Baba, K. and Hayakawa, M. (1996) Computational Results of the Effect of Localized Ionospheric Perturbations on Subionospheric VLF Propagation. Journal of Geophysical Research, 101, 10985-10993. https://doi.org/10.1029/96JA00026

[7] Rodger, C.J., Thomson, N.R. and Dowden, R.L. (1996) A Search for ELF/VLF Activity Associated with Earthquakes Using ISIS Satellite Data. Journal of Geophysical Research, 101, 13369-13378. https://doi.org/10.1029/96JA00078 
[8] Molchanov, O.A. and Hayakawa, M. (1998) Subionospheric VLF Signal Perturbations Possibly Related to Earthquakes. Journal of Geophysical Research, 103, 17,489-17,504. https://doi.org/10.1029/98JA00999

[9] Molchanov, O.A., Hayakawa, M., Ondoh, T. and Kawai, E. (1998) Precursory Effects in the Subionospheric VLF Signals for the Kobe Earthquake. Physics of the Earth and Planetary Interiors, 105, 239-248. https://doi.org/10.1016/S0031-9201(97)00095-2

[10] Clilverd, M.A., Rodger, C.J. and Thomson, N.R. (1999) Investigating Seismo-Ionospheric Effects on a Long Subionospheric Path. Journal of Geophysical Research, 104, 28171-28179. https://doi.org/10.1029/1999JA900285

[11] Hayakawa, M. (1999) Atmospheric and Ionospheric Electromagnetic Phenomena Associated with Earthquakes. Terra Sci. Pub. Co., Tokyo, 996.

[12] Rodger, C.J. (1999) Red Sprited, Upward Lightning, and VLF Perturbations. Reviews of Geophysics, 37, 317-336. https://doi.org/10.1029/1999RG900006

[13] Hayakawa, M. and Molchanov, O.A. (2002) Seismo Electromagnetics: Lithosphere-Atmosphere-Ionosphere Coupling. TERRAPUB, Tokyo, 477.

[14] Shvets, A.V., Hayakawa, M., Molchanov, O.A. and Ando, Y. (2004) A Study of Ionospheric Response to Regional Seismic Activity by VLF Radio Sounding. Physics and Chemistry of the Earth, 29, 627-637. https://doi.org/10.1016/j.pce.2003.08.063

[15] Hayakawa, M., Ohta, K., Nickolaenko, A.P. and Ando, Y. (2005) Anomalous Effect in Schumann Resonance Phenomena Observed in Japan, Possibly Associated with the Chi-Chi Earthquake in Taiwan. Annales Geophysicae, 23, 1335-1346. https://doi.org/10.5194/angeo-23-1335-2005

[16] Hayakawa, M., Kasahara, Y., Nakamura, T., Hobara, Y., Rozhnoi, A., Solovieva, M. and Molchanov, O.A. (2010) A Statistical Study on the Correlation between Lower Ionospheric Perturbations as Seen by Subionospheric VLF/LF Propagation and Earthquakes. Journal of Geophysical Research Atmospheres, 115, A9.

https://doi.org/10.1029/2009JA015143

[17] Rozhnoi, A., Molchanov, O., Solovieva, M., Gladyshev, V., Akentieva, O., Berthelier, J.J., Parrot, M., Lefeuvre, F., Biagi, P.F., Castellana, L. and Hayakawa, M. (2007) Possible Seismo-Ionosphere Perturbations Revealed by VLF Signals Collected on Ground and on a Satellite. Natural Hazards and Earth System Sciences, 7, 617-624. https://doi.org/10.5194/nhess-7-617-2007

[18] Horie, T., Maekawa, S., Yamauchi, T. and Hayakawa, M. (2007) A Possible Effect of Ionospheric Perturbations Associated with the Sumatra Earthquake, as Revealed from Subionospheric Very-Low-Frequency (VLF) Propagation (NWC-Japan). International Journal of Remote Sensing, 28, 3133-3139.

https://doi.org/10.1080/01431160601094476

[19] Horie, T., Yamauchi, T., Yoshida, M. and Hayakawa, M. (2007) The Wavelike Structures of Ionospheric Perturbation Associated with Sumatra Earthquake of 26 December 2004, as Revealed from VLF Observation in Japan of NWC Signals. Journal of Atmospheric and Solar-Terrestrial Physics, 69, 1021-1028. https://doi.org/10.1016/j.jastp.2007.03.012

[20] Nemec, F., Santolik, O. and Parrot, M. (2009) Decrease of Intensity of ELF/VLF Waves Observed in the Upper Ionosphere Close to Earthquakes: A Statistical Study. Journal of Geophysical Research, 114, A04303.

https://doi.org/10.1029/2008JA013972

[21] Hayakawa, M., Molchanov, O.A., Ondoh, T. and Kawai, E. (1996) Anomalies in the Sub-Ionospheric VLF Signals for the 1995 Hyogo-Ken Nanbu Earthquake. Journal 
of Physics of the Earth, 44, 413-418. https://doi.org/10.4294/jpe1952.44.413

[22] Hayakawa, M., Molchanov, O.A., Ondoh, T. and Kawai, E. (1996) The Precursory Signature Effect of the Kobe Earthquake on VLF Subionospheric Signals. Journal of the Communications Research Laboratory, 43, 169-180. https://doi.org/10.1109/ELMAGC.1997.617080

[23] Maekawa, S., Horie, T., Yamauchi, T., Sawaya, T., Ishikawa, M., et al. (2006) A Statistical Study on the Effect of Earthquakes on the Ionosphere, Based on the Subionospheric LF Propagation Data in Japan. Annales Geophysicae, European Geosciences Union, 24, 2219-2225. https://doi.org/10.5194/angeo-24-2219-2006

[24] Kasahara, Y., Muto, F., Hobara, Y. and Hayakawa, M. (2010) The Ionospheric Perturbations Associated with Asian Earthquakes as Seen from the Subionospheric Propagation from NWC to Japanese Stations. Natural Hazards and Earth System Sciences, 10, 581-588. https://doi.org/10.5194/nhess-10-581-2010

[25] Chakrabarti, S.K., Saha, M., Khan, R., Mandal, S., Acharyya, K. and Saha, R. (2005) Possible Detection of Ionospheric Disturbances during Sumatra-Andaman Islands Earthquakes in December. Indian Journal of Radio \& Space Physics, 34, 314-317.

[26] Sasmal, S. and Chakrabarti, S.K. (2009) Ionospheric Anomaly Due to Seismic Activities I: Calibration of the VLF Signal of VTX $18.2 \mathrm{kHz}$ Station from Kolkata. Natural Hazards and Earth System Sciences, 9, 1403-1408. https://doi.org/10.5194/nhess-9-1403-2009

[27] Chakrabarti, S.K. and Sasmal, S. (2010) Ionospheric Anomaly Due to Seismic Activities Part 2: Evidence from D-Layer Preparation and Disappearance Times. Natural Hazards and Earth System Sciences, 10, 1751-1757.

https://doi.org/10.5194/nhess-10-1751-2010

[28] Sasmal, S., Chakrabarti, S.K. and Ray, S. (2014) Unusual Behavior of VLF Signals Observed from Sitapur during the Earthquake at Honshu, Japan on 11 March, 2011. Indian Journal of Physics, 88, 1013-1019. https://doi.org/10.1007/s12648-014-0520-8

[29] Chakraborty, S., Sasmal, S., Basak T., Ghosh, S., Palit, S., Chakrabarti, S.K. and Ray, S. (2017) Numerical Modeling of Possible Lower Ionospheric Anomalies Associated with Nepal Earthquake in May, 2015. Advances in Space Research, 60, 1787-1796. https://doi.org/10.1016/j.asr.2017.06.031

[30] Ghosh, S., Chakraborty, S., Sasmal, S., Basak, T., Chakrabarti, S.K. and Samanta, A. (2019) Comparative Study of the Possible Lower Ionospheric Anomalies in Very Low Frequency (VLF) Signal during Honshu, 2011 and Nepal, 2015 Earthquakes. Geomatics, Natural Hazards and Risk, 10, 1596-1612.

https://doi.org/10.1080/19475705.2019.1595178

[31] Ray, S., Chakrabarti, S.K., Mondal, S.K. and Sasmal, S. (2011) Ionospheric Anomaly Due to Seismic Activities III: Correlation between Night Time VLF Amplitude Fluctuations and Effective Magnitudes of Earthquakes in Indian Sub-Continent. Natural Hazards and Earth System Sciences, 11, 2699-2704.

https://doi.org/10.5194/nhess-11-2699-2011

[32] Ray, S., Chakrabarti, S.K. and Sasmal, S. (2012) Precursory Effects in the Nighttime VLF Signal Amplitude for the 18th January, 2011 Pakistan Earthquake. Indian Journal of Physics, 86, 85-88. https://doi.org/10.1007/s12648-012-0014-5

[33] Hayakawa, M., Raulin, J.P., Kasahara, Y., Bertoni, F.C.P., Hobara, Y. and Guevara-Day, W. (2011) Ionospheric Perturbations in Possible Association with the 2010 Haiti Earthquake, as Based on Medium-Distance Subionospheric VLF Propagation Data. Natural Hazards and Earth System Science, 11, 513-518. 
https://doi.org/10.5194/nhess-11-513-2011

[34] Miyaki, K., Hayakawa, M. and Molchanov, O.A. (2002) The Role of Gravity Waves in the Lithosphere-Ionosphere Coupling, as Revealed from the Subionospheric LF Propagation Data. In: Hayakawa, M. and Molchanov, O., Eds., Seismo-Electromagnetics: Lithosphere-Atmosphere-Ionosphere Coupling, TERRAPUB, Tokyo, 29-232.

[35] Molchanov, O.A., Hayakawa, M. and Miyaki, K. (2001) VLF/LF Sounding of the Lower Ionosphere to Study the Role of Atmospheric Oscillations in the Lithosphere-Ionosphere Coupling. Advances in Polar Upper Atmosphere Research, 15, 146-158.

[36] Rozhnoi, A., Solovieva, M.S., Molchanov, O.A. and Hayakawa, M. (2004) Middle Latitude LF (40 kHz) Phase Variations Associated with Earth-Quakes for Quiet and Disturbed Geomagnetic Conditions. Physics and Chemistry of the Earth, 29, 589-598. https://doi.org/10.1016/j.pce.2003.08.061

[37] Rozhnoi, A., Solovieva, M., Molchanov, O.A., Biagi, P.F. and Hayakawa, M. (2007) Observation Evidences of Atmospheric Gravity Waves Induced by Seismic Activity from Analysis of Subionospheric LF Signal Spectra. Natural Hazards and Earth System Sciences, 7, 625-628. https://doi.org/10.5194/nhess-7-625-2007

[38] Shvets, A.V., Hayakawa, M. and Maekawa, S. (2004) Results of Subionospheric Radio LF Monitoring Prior to the Tokachi $(\mathrm{m}=8$, Hokkaido, 25 September 2003) Earthquake. Natural Hazards and Earth System Sciences, 4, 647-653.

https://doi.org/10.5194/nhess-4-647-2004

[39] Muto, F., Kasahara, Y., Hobara, Y., Hayakawa, M., Rozhnoi, A., Solovieva, M. and Molchanov, O.A. (2009) Further Study on the Role of Atmospheric Gravity Waves on the Seismo-Ionospheric Perturbations as Detected by Subionospheric VLF/LF Propagation. Natural Hazards and Earth System Sciences, 9, 1111-1118. https://doi.org/10.5194/nhess-9-1111-2009

[40] Blaunstein, N. and Hayakawa, M. (2009) Short-Term Ionospheric Precursors of Earthquakes Using Vertical and Oblique Ionosondes. Physics and Chemistry of the Earth, Parts A/B/C, Electromagnetic Phenomena Associated with Earthquakes and Volcanoes, 34, 496-507. https://doi.org/10.1016/j.pce.2008.07.002

[41] Korepanov, V., Hayakawa, M., Yampolski, Y. and Lizunov, G. (2009) AGW as a Seismo-Ionospheric Coupling Responsible Agent. Physics and Chemistry of the Earth, Parts $A / B / C, 34,485-495$. https://doi.org/10.1016/j.pce.2008.07.014

[42] Chakraborty, S., Sasmal, Chakrabarti, S.K. and Bhattacharya, A. (2018) Observational Signatures of Unusual Outgoing Longwave Radiation (OLR) and Atmospheric Gravity Waves (AGW) as Precursory Effects of May 2015 Nepal Earthquakes. Journal of Geodynamics, 113, 43-51. https://doi.org/10.1016/j.jog.2017.11.009

[43] Yang, S.S., Asano, T. and Hayakawa, M. (2019) Abnormal Gravity Wave Activity in the Stratosphere Prior to the 2016 Kumamoto Earthquakes. Journal of Geophysical Research: Space Physics, 124, 1410-1425. https://doi.org/10.1029/2018JA026002

[44] Yang, S.-S. and Hayakawa, M. (2020) Gravity Wave Activity in the Stratosphere before the 2011 Tohoku Earthquake as the Mechanism of Lithosphere-Atmosphere-Ionosphere Coupling. Entropy, 22, 110.

https://doi.org/10.3390/e22010110

[45] Laštovička, J. and Pechala, F. (1986) Effects of the IMF Sector Structure in the Midlatitude Troposphere and Stratosphere. Studia Geophysica et Geodaetica, 30, 394-403. https://doi.org/10.1007/BF01646382 
[46] Laštovička, J. (1996) Effects of Geomagnetic Storms in the Lower Ionosphere, Middle Atmosphere and Troposphere. Journal of Atmospheric and Terrestrial Physics, 58, 831-843. https://doi.org/10.1016/0021-9169(95)00106-9

[47] Danilov, A.D. and Laštovička, J. (2001) Effects of Geomagnetic Storms on the Ionosphere and Atmosphere. International Journal of Geomagnetism and Aeronomy, 2, 209-224.

[48] Chenette, D.L., Datlowe, D.W., Robinson, R.M., Schumaker, T.L., Vondrak, R.R. and Winningham, J.D. (1993) Atmospheric Energy Input and Ionization by Energetic Electrons during the Geomagnetic Storm of 8-9 November 1991. Geophysical Research Letters, 20, 132. https://doi.org/10.1029/93GL01342

[49] Stoker, P.H. (2013) Energetic Electron Power Flux Deposition at Sanae (L = 4.0) from Riometer Recording. Journal of Geophysical Research, 98, 19111-19116. https://doi.org/10.1029/93JA01951

[50] Tatsuta, K., Hobara, Y., Pal, S. and Balikhin, M. (2015) Sub-Ionospheric VLF Signal Anomaly Due to Geomagnetic Storms: A Statistical Study. Annales Geophysicae, 33, 1457-1467. https://doi.org/10.5194/angeo-33-1457-2015

[51] Hayakawa, M. (2007) VLF/LF Radio Sounding of Ionospheric Perturbations Associated with Earthquakes. Sensors, 7, 1141-1158. https://doi.org/10.3390/s7071141

[52] Rozhnoi, A., Solovieva, M. and Hayakawa, M. (2013) VLF/LF Signals Method for Searching of Electromagnetic Earthquake Precursors. In: Hayakawa, M., Ed., Earthquake Prediction Studies. Seismo Electromagnetics, TERRAPUB, Tokyo, 31-48.

[53] Gufeld, I.L., Rozhnoi, A.A., Tyumensev, S.N., Sherstuk, S.V. and Yampolsky, V.S. (1992) Radiowave Disturbances in Period to Rudber and Rachinsk Earthquakes. Physics of the Solid Earth, 28, 267-270.

[54] Santos, C., Galvao, C., Suzuki, K. and Trigo, R. (2001) Matsuyama City Rainfall Data Analysis Using Wavelet Transform. Annual Journal of Hydraulic Engineering, 45, 211-216. https://doi.org/10.2208/prohe.45.211

[55] Yamashita, C., England, S.L., Immel, T.J. and Chang, L.C. (2013) Gravity Wave Variations during Elevated Stratopause Events Using SABER Observations. Journal of Geophysical Research: Atmospheres, 118, 5297-5306. https://doi.org/10.1002/jgrd.50474

[56] Thurairajah, B., Bailey, S.M., Cullens, C.Y., Hervig, M.E. and Russell, J.M. (2014) Gravity Wave Activity during Recent Stratospheric Sudden Warming Events from SOFIE Temperature Measurements. Journal of Geophysical Research: Atmospheres, 119, 8091-8103. https://doi.org/10.1002/2014JD021763

[57] Yang, S.-S., Pan, C.J., Das, U. and Lai, H.C. (2015) Analysis of Synoptic Scale Controlling Factors in the Distribution of Gravity Wave Potential Energy. Journal of Atmospheric and Solar-Terrestrial Physics, 135, 126-135. https://doi.org/10.1016/j.jastp.2015.10.020

[58] Lal, M. (2006) Study of Geomagnetic Storm Induced Acoustic Gravity Waves over Equatorial Latitude. Indian Journal of Radio and Space Physics, 35, 174-180.

[59] Yang, S.-S., Potirakis, S.M., Sasmal, S. and Hayakawa, M. (2020) Natural Time Analysis of Global Navigation Satellite System Surface Deformation: The Case of the 2016 Kumamoto Earthquakes. Entropy, 22, 674.

https://doi.org/10.3390/e22060674 